\title{
基于共建共赢的中欧班列高质量发展战略研究
}

\author{
陈云 $^{1}$, 卢春房 ${ }^{2}$, 盛黎明 ${ }^{1}$, 刘延宏 $^{1}$ \\ （1. 中国国家铁路集团有限公司工程管理中心，北京 100844；2. 中国铁道学会，北京 100844）
}

\begin{abstract}
摘要：本文对新时期中欧班列经济功能定位进行了阐述，梳理了中欧班列营运现状及面临的主要风险挑战，分析了沿线贸易 环境和基础设施建设、国际多边沟通合作、货源支撑及物流服务整体水平以及市场化运作等中欧班列高质量发展的影响因素; 对基于共建共赢的中欧班列高质量发展实践进行深入思考并提出三条发展路径: 推动中欧班列数量和运营质量同步提升, 实 施 “班列运输 + 物流枢纽建设 + 配套服务能力” 综合发展策略和构建国际贸易、产业升级与金融服务多元价值链。最后, 从 加强协调合作、积极推进通关便利, 优化运输组织、提供全程物流服务, 完善价格机制、吸引多渠道资金投入以及推进平台 建设、加强人才培养和科技创新等方面提出保障措施, 以期对我国促进中欧班列高质量可持续性发展提供参考。
\end{abstract}

关键词: 共建共赢; 中欧班列; 高质量发展战略

中图分类号：F532.4 文献标识码：A

\section{High-Quality Development of China Railway Express Based on Win-Win Co-construction}

\author{
Chen Yun ${ }^{1}$, Lu Chunfang ${ }^{2}$, Sheng Liming ${ }^{1}$, Liu Yanhong ${ }^{1}$ \\ (1. Engineering Management Center, China State Railway Group Co., Ltd., Beijing 100844, China; \\ 2. China Railway Society, Beijing 100844, China)
}

\begin{abstract}
This paper expounds upon the economic function definition of China Railway Express in the new era and sorts out its current operating situation and major risks and challenges. The main influencing factors of China Railway Express toward high-quality development are analyzed, such as the trade environment and infrastructure construction along the line, international multilateral communication and cooperation, goods supply support and logistics service level, as well as market-oriented operation. The practice of China Railway Express toward high-quality development is deeply explored based on win-win co-construction, and three development paths are presented: to promote both the quantity and operational quality of the China Railway Express; to implement the comprehensive development strategy of "train transportation + logistics hub construction + supporting service capacity"; and to build a multi-value chain of international trade, industrial upgrading, and financial services. Finally, this paper proposes safeguard measures from four aspects, namely strengthening coordination and cooperation and actively promoting customs clearance convenience; optimizing transportation organization and providing whole-process logistics services; improving price mechanism to attract multichannel capital investment; promoting platform construction and strengthening talents as well as scientific and technological innovation, in order to provide reference for the boosting of the high-quality development of China Railway Express.
\end{abstract}

Keywords: win-win co-construction; China Railway Express; strategy of high-quality development

收稿日期 : 2020-03-29; 修回日期 : 2020-05-02

通讯作者: 陈云, 中国国家铁路集团有限公司工程管理中心高级工程师, 研究方向为铁路科技管理与工程建设信息化;

E-mail: ch.yun@163.com

资助项目：中国工程院咨询项目“ “一带一路”交通基础设施发展战略研究” (2018-XZ-11)

本刊网址 : www.engineering.org.cn/ch/journal/sscae 


\section{一、前言}

作为 “一带一路” 倡议的重要组成部分、国际 物流陆路的重要载体和运输骨干，中欧班列（含中 亚班列）自 2011 年开行以来，受到国内外客户的 青睐, 发展势头迅猛, 规模数量呈现井喷式增长。 中欧班列的常态化、规模化营运，连接了活跃的东 亚经济圈和发达的欧洲商贸圈, 为时效性较强、附 加值较高的货物生产商和贸易商提供了新的选择, 有力促进了中国对外开放和 “一带一路” 沿线国家 经贸往来, 得到了国际社会的普遍关注和高度赞誉。 但是，目前中欧班列也存在着通关时间长、配套基 础设施发展慢、制约发展因素多等风险与挑战。在 此背景下, 研究中欧班列如何提升市场整体竞争力, 实现高质量可持续性发展，具有重要理论价值和现 实指导意义。

\section{二、中欧班列营运现状及面临的主要风险 挑战}

中欧班列是中国与欧洲以及 “一带一路”沿 线国家之间开行的集装箱铁路国际联运列车，是深 化我国与沿线国家经贸合作的重要载体和推进 “一 带一路”建设的主要抓手和新引擎。中欧班列的成 功开行为中欧国际贸易提供了海运、空运以外的 选择, 为亚欧经贸增长带来了旺盛的货物运输需 求 [1]。同时，中国是欧盟的第二大贸易伙伴，预计 到 2025 年，中国与 “一带一路” 国家间的贸易总额、 与欧洲的双边贸易额将有新的突破, 这迫切需要在 完善海路运输的同时，加快陆路运输通道建设。

\section{（一）新时期中欧班列经济功能定位与分析}

1. 推动和巩固沿线国家经贸稳步发展的助力器 中欧班列自开行以来，已成为沿线国家间贸易 运输方式的有益补充。2019 年，中国与开通中欧班 列的相关国家进出口贸易总额近 8000 亿美元。未 来，在中欧班列通达范围拓展、服务能力提升、物 流商贸金融增值发展的共同驱动下，中欧班列有望 更好发挥国际贸易稳增的助力推动作用。

2. 构建全方位对外开放格局的领跑者

随着全球一体化的进程，国际贸易规则体系和 融资机制趋于重构，沿线各国都需要在国际经济贸
易往来合作的领域实现多元化的探索。我国中西部 地区在区域协调发展的框架背景下也在努力打造内 陆开放高地, 以更好融入全方位对外开放的新格局, 提升主动应对能力。

\section{3. 探求深化国际优势产能合作的敲门砖}

在我国 “一带一路”建设向纵深发展的形势下, 交通互联互通为我国产业 “走出去” 进行国际产能 合作提供了良好条件。目前，中欧班列已抵达欧洲 多个城市, 国内大型物流运输企业以及汽车、冶金、 钢铁及有色金属等行业制造企业，都已在生产制造 中心、物流平台服务和网络架构以及基础设施建设 等方面 “投石问路”，探索合作潜能 [2]。

4. 推进铁路供给侧结构性深化改革的生力军

随着供给侧结构性改革的深入，供需结构调整 的态势也在铁路货运行业呈现, 创新铁路运输经营 管理组织模式，提升运输链效率，组织产品开发模 式，以不断提高其市场竞争力。

\section{5. 实现各国互联互通的示范}

构建 “丝绸之路经济带” 要创新合作模式, 加 强 “五通”，即政策沟通、设施联通、贸易畅通、 资金融通和民心相通。“一带一路”建设以 “五通” 为支撑手段，其中基础设施的互联互通是基础。 中欧班列将原来没有联通的国家实现了互联，增 进了交流合作，成为其他四项联通的示范，将带 动其发展。

\section{（二）中欧班列营运现状}

1. 中欧班列开行数量和范围

中欧班列自开行以来, 从无到有, 快速发展, 2011 年至 2019 年分别开行 17 列、42 列、80 列、 308 列、815 列、1702 列、3673 列、6300 列、 8225 列。其中, 中欧班列 2018 年开行的数量和 2011-2017 年开行总数量接近，2019 年实现回程班 列数量与去程班列数量之比达到 $82 \%$ (见图 1)。截 至 2020 年 2 月底, 中国境内开行中欧班列的城市 近 60 个，累计开行超过 100 列的城市有 24 个; 班 列通达欧洲 18 个国家共 57 个城市，对于促进中国 与亚欧沿线国家的贸易增长起到重要作用。

\section{2. 中欧班列开行通道和开行口岸}

中欧班列按出境口岸的不同形成了西、中、东 3 条国际通道, 分别从阿拉山口（霍尔果斯）口岸、 二连浩特口岸和满洲里口岸出境。经阿拉山口的 


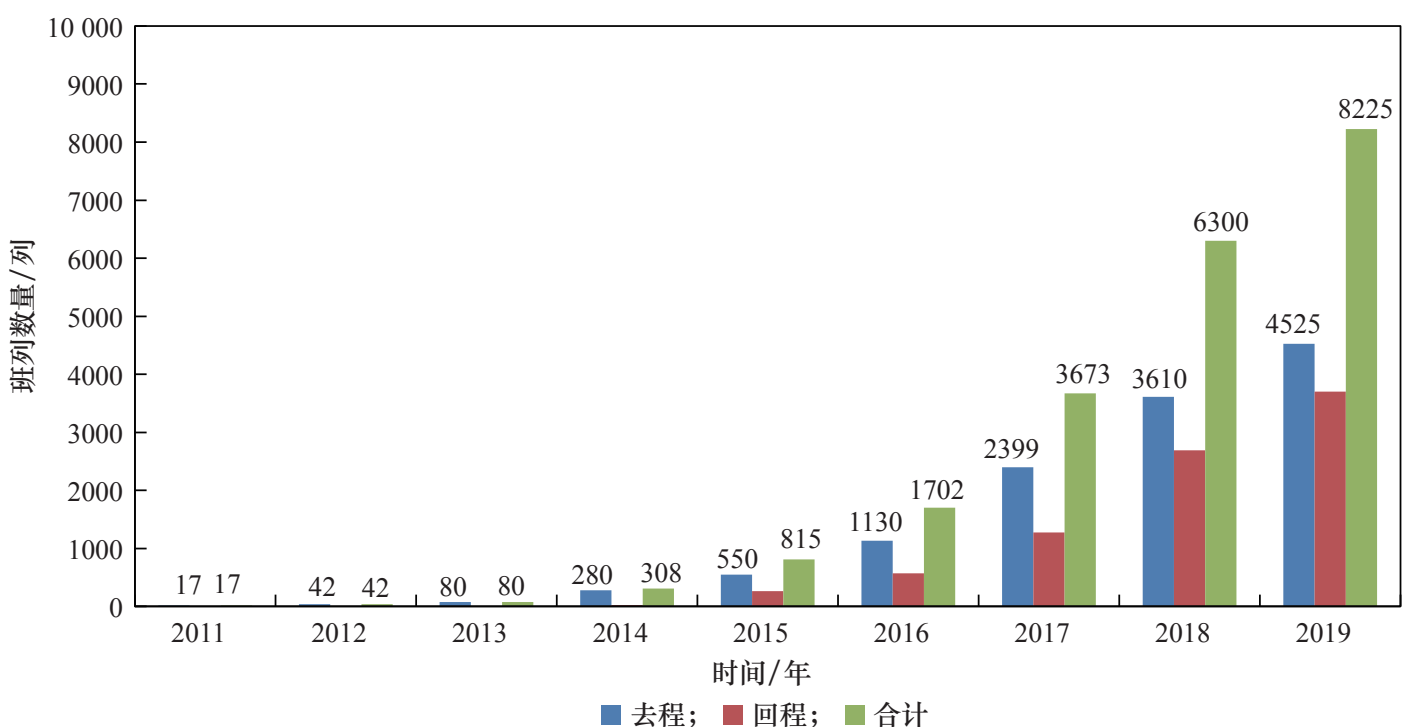

图 $12011-2019$ 年中欧班列营运班列数量

西部通道按运输路径又分为北 (俄罗斯、西北欧方 向)、中 (高加索、里海、中欧方向)、南（伊朗、 土耳其、南欧方向 ) 3 条通路。开行口岸主要为四 个: 满洲里、二连浩特、阿拉山口、霍尔果斯。

\section{3. 中欧班列运送货物标箱}

截至 2019 年 12 月, 中欧班列自开行以来, 累计 运送货物 $1.835 \times 10^{6}$ 标箱, 其中, 去程 $1.111 \times 10^{6}$ 标箱, 回程 $7.24 \times 10^{5}$ 标箱。

\section{（三）中欧班列营运面临的主要风险挑战}

\section{1. 经营风险}

（1）运营成本高，存在无序竞争。很多企业在 跨国运输的项目上依旧倾向于传统模式的海运, 在 与海运竞争资源时, 中欧班列运营成本偏高。此外, 无序竞争比较严重的情况也造成运营成本居高不 下, 内陆多个城市纷纷开行 “ $X$ 新欧”, 导致争抢 货源，运力浪费。

（2）海关手续复杂，通关效率低。通关是中欧 班列经过口岸站时作业环节中的重要一环, 货物通 过海关的基本流程包括报关、审单、查验、放行, 由于各国海关自动化程度、工作人员业务及审单效 率存在差异, 导致通关实施一体化有较大难度。通 关效率直接影响中欧班列的运行效率, 进而对其营 运状况带来直接影响。

（3）返程货源组织有难度。回程货源的短缺及 欠稳定性也给经营和交易带来一定风险。究其原因
是物流成本偏高, 运输范围存在的局限性使货源组 织在激烈的市场竞争下变得较为困难; 此外, 在中 欧班列沿线国家，相比于传统的海运或空运的运输 形式, 班列运输需要逐步地打开市场。

\section{2. 时间风险}

（1）部分路段运行速度缓慢。目前，大部分班 列运行线路的中间部分路段设施相对比较落后, 单 线铁路数量众多, “两端快、中间慢” 成为常态, 严重降低了列车营运的平均时速。例如, 班列行驶 出阿拉山关口之后速度迅速减缓, 直到进入波兰之 后，车速才提高。

(2) 换轨时间较长。我国铁路与国外铁路在轨 距、车辆规格、载重制式、运输规范等方面标准不 同, 列车在运行过程中通过边境口岸需要进行换轨, 此外，货物换装时的短装、溢装和甩货，这些都严 重影响作业时间和效率, 导致运输延迟。

(3) 通关时间较长。由于国家运行机制不同, 不同国家在检验检疫、海关等方面要求不同，而中 欧班列通关涉及的单证较多, 信息录入效率较低。 一旦无法及时按照各国口岸要求准确完整地提交相 关单证，货物就可能滞留，延长通关时间 [3]。

\section{3. 安全风险}

(1) 长途运输对货物的安全造成隐患。班列每 箱、每趟货物品类不一, 由于中欧班列运行距离 长, 途经国家多, 运输过程中需要多次转关换轨, 在开箱验货、装卸车作业时易产生磕碰、倾斜或 
倒塌等损坏和危及货物安全的问题。对于电子设备 的防水措施若不到位, 则会直接导致货品失去其使 用价值。

（2）自然气候条件。相对于海运、空运等运输 方式, 铁路运输虽然受天气影响较小, 但在遭遇泥 石流、山体滑坡、洪水、强烈暴风雨雪等极端自然 灾害时，也可能会对货物安全带来影响。

\section{4. 其他风险}

中欧班列目前开通的线路及规划线路沿途经过 的国家和地区众多，其体制、文化以及经济环境各 不相同, 另外, 还有个别国家的政治环境长期动荡 不安, 难免遭受大国博弯的波及从而带来地缘政治 方面潜在的其他风险。

\section{三、影响中欧班列高质量发展的重要因素分析}

中欧班列开行以来, 开行规模持续扩大, 开行 质量显著提升, 业务范围不断拓展, 推动中欧班列 提质增效向纵深发展, 着力打造 “方便快捷、安全 高效、绿色环保” 的国际运输通道。在进行中欧班 列高质量可持续性营运发展思路研究时, 应对其影 响因素予以考究分析。

\section{（一）沿线贸易环境和基础设施建设}

亚欧大陆拥有世界 $75 \%$ 的人口，地区生产总 值约占世界总额的 $60 \%$, 东面是活跃的东亚经济圈, 西面是发达的欧洲经济圈, 中间广大腹地经济发展 富有潜力, 巨大的国际物流需求为铁路国际联运的 发展提供了广阔的市场空间。“一带一路”沿线各 国基础设施实现互联互通、提升经贸合作水平、稳 定运营模式、完善合作机制和利益协调机制, 将给 亚欧大陆国际货物运输带来旺盛的需求, 并促进中 欧班列进一步快速发展。

\section{（二）国际多边沟通合作}

2017 年 4 月, 中国、俄罗斯、白俄罗斯、德国、 波兰、蒙古国、哈萨克斯坦等 7 国铁路正式签署《关 于深化中欧班列合作协议》, 这是第一个由中国铁 路主导的国际铁路合作机制, 对于铁路更好服务和 支持 “一带一路” 建设具有重要意义。同时，应依 托国际组织加强对中欧班列运输组织的协调沟通, 推动国际运输标准体系建设。

\section{（三）货源支撑及物流服务整体水平}

班列数量的增加、开行密度的加大、货物品类 的丰富以及运输规模的扩大都积极促进了我国 “走 出去” 企业的对外贸易发展, 应不断加强与沿线国 家政府相关方面的合作，推动中欧班列向境外经贸 合作区、工业园区及自由港区延伸，吸引更多货源 通过中欧班列运输, 进一步强化货源支撑、提高货 运及物流服务整体水平。加快建设 “一带一路” 沿 线货物集散点, 大力开发回程货源, 不断完善创新 运营模式及配套设施 [4]。

\section{（四）市场化运作}

推动中欧班列市场化运作，让市场在班列发展 中起决定性作用, 既需要在提高中欧班列换装效率 速度、加快通关便利化步伐、提升其开行营运稳定 性常态化方面下功夫, 更需着力建立合理价格机制、 完善配套设施以及创新运营模式，包括适当的政府 补贴、调动企业的积极性与参与度、拓展国际合作 渠道、开辟行业协同联动空间及延伸班列营运的辐 射范围和带动效应等。

\section{四、“一带一路” 背景下中欧班列实现高质 量发展的路径探索}

目前, 中欧班列已成为 “一带一路” 建设的标 志性成果, 其主要成果体现在: 开行数量快速增长, 货物品类日益丰富, 国际铁路合作机制成功创建, 国内企业合作平台顺利搭建, 运输保障体系框架稳 步构建, 全程物流服务体系初步建立, 品牌效应不 断扩大, 运行安全得到确保。在 “一带一路” 背景 下, 探索如何践行中欧班列实现高质量发展的路径, 可从以下方面思考。

\section{（一）推动中欧班列数量和运营质量同步提升}

持续推动东部、中部和西部核心营运枢纽协同 发展, 根据各自特点形成重点突出、优势互补的货 物集结中心，加强与沿线国家合作的跨境经济合作 区、边境经济合作区以及产业聚集区的协调联动, 打造一批具有较强国际影响力的现代物流枢纽, 如 中白工业园区、中哈霍尔果斯国际边境合作中心等, 加快形成 “干支结合、枢纽集散” 的班列组织方式, 促进班列开行由 “点对点” 向 “枢纽对枢纽” 转变。 
2019 年 9 月, 23 个国家物流枢纽落定, 遍及中东部、 中部、西北和东北地区, 涵盖陆港型、空港型、港 口型、生产服务型、商贸服务型、陆上边境口岸等 6 种类型, 为 “一带一路” 建设、为中欧班列商贸 通道往来提供坚实保障。

注重量质并举, 推动中欧班列开行数量和运营 质量的同步提升。依据线路开行情况、境外货源集 散点及铁路枢纽基础设施质量, 考虑跨国多式联运 因素，尽快对开行的货物列车线路结构和布局进行 进一步的合理优化, 根据货主的运输时限、货品特 性, 逐步细化、规范、完善货物班列分类, 提供不 同档次、满足不同需求的货运产品, 提高中欧班列 营运网络效能，推动运营质量进一步提升。

\section{（二）实施 “班列运输 + 物流枢纽建设 + 配套服务 能力” 综合发展策略}

以国际产能和装备制造合作为契机，推动中欧 班列向我国在沿线国家建设的境外经贸合作区、有 关国家工业园区、自由港区延伸，吸引更多货源通 过中欧班列运输, 打造中欧班列为以货品运输为载 体、班列国际物流运输利益共同体为成果的健康有 序发展模式。

班列开行应与现代物流中心建设结合, 发挥 其物流枢纽效应。鼓励国内企业在国外重要节点城 市以及产能合作密切城市, 通过收购、合资、合作 等方式，围绕物流基地、分拨集散中心、海外仓等 加强沿线各枢纽节点的基础设施和物流配套设施建 设, 打造一批具有多式联运功能的大型综合物流基 地, 完善冷链物流基地、城市配送中心布局, 支持 在物流基地建设具有海关、检验检疫等功能的铁路 口岸。探索与国外企业共建海外物流仓, 利用当地 企业 “本土化” 的优势, 持续优化物流流程, 有效 降低国际联运全程物流成本，提高班列的整体实力 与市场竞争力 [5]。

\section{（三）构建国际贸易、产业升级与金融服务多元价 值链}

\section{1. 拓展商贸增值功能}

新一轮科技革命和产业变革渗透到全球贸易的 各方面, 运输物流链成为生产贸易系统中不可或缺 的重要一环, 中欧班列的开行带动了与沿线国家经
贸往来的活跃发展, 拉动跨境区域商贸消费, 促进 沿线国家区域生产贸易系统的深度融合，对亚欧大 陆生产贸易格局的变动和全球生产贸易供应链的重 构释放出强烈信号, 伴随中欧班列运输效能的不断 提升, 应注重挖掘班列商贸增值功能、提升物流增 值服务，加快中欧班列与开行城市区域范围商贸物 流一体化、进出口贸易一体化的功能对接, 拓展 国际代理采购、国际保险理赔、货物质押等增值 服务, 支持跨境货物加工与转口贸易, 创造其经济 溢出效应。

\section{2. 带动沿线国家产业升级和经济发展}

促进中欧班列与中国同 “一带一路” 沿线国家, 以及沿线国家相互之间的互惠互利合作相结合, 拓 展以铁路运输为纽带的多式联运业务, 利用并发挥 海运、公路、铁路运输的各自优势，实现中欧班列 与其他运输方式的联程联运和有效衔接, 形成有利 于物流信息交换、经济要素流动的国际运输通道, 增强中欧班列开行城市的辐射集聚效应, 帮助沿线 国家汇聚包含信息、物流、资金、人才等众多资源, 探索与当地产业深度有机融合, 实现乘数效应的持 续释放, 带动当地城市产业升级, 推动沿线国家经 济发展, 有效促进民生改善, 使沿线国家能从跨境 运输中获取切实利益。

\section{3. 筑造跨境泛金融生态圈}

中欧班列的营运及相关国际物流运输平台的建 立发展需要金融服务体系 [1] 与之匹配，包括金融 规则、资金结算方式、交付形式、理赔、保险业务 等。由于铁路运单不具备物权凭证属性而带来一定 的贸易障碍，线下模式 “一单制” 虽然保障了货物 运输全程可控, 但面临着参与方众多、跨越不同管 辖区域、数据分散零乱、沟通成本高、流程协同低 效等一系列问题。近期, 中欧班列多式联运 “一单 制” 跨境区块链平台在四川自贸区推出, 平台将区 块链技术与中欧班列多式联运 “一单制” 各业务环 节相结合, 通过数据的联通和互验, 通过流程再造 和制度创新赋予了 “一单制” 物权属性, 以逐步破 解国际铁路联运不能进行单证交易、多种运输方式 组织难、中小外贸企业融资难等问题, 实现了跨境 结算、融资、关税等一揽子通关与金融便利。

展望未来, 平台还有望引入口岸监管、境内外 金融机构、进出口贸易商以及中欧班列沿线的物流 
服务商、咨询、认证、保险、法律等各方共同参与, 组成联盟, 共同搭建和运营平台, 探索陆运国际贸 易新规则, 筑造互信安全、高效便捷、开放共享的 跨境泛金融生态圈。

\section{五、促进中欧班列高质量发展的保障措施 建议}

顺应市场需求，为新阶段中欧班列高质量发展 营运管理提供科学评判依据 [6], 2018 年出台的《中 欧班列高质量发展评价指标》构建了以质量和安全 为导向的中欧班列指标体系, 提出对班列运行质量 及效益进行评价的 5 个参数指标, 分别是重箱率、 回程比率、发送量、计划兑换率和运输安全, 应在 实践操作过程中予以规范和完善。促进中欧班列高 质量发展, 应从以下方面实施保障措施。

\section{（一）加强协调合作，积极推进通关便利}

加强各部门、各地方政府的沟通协调，充分发 挥政府、市场、企业的作用，为中欧班列营造良好 运营环境和发展条件。中欧班列贸易通道的深化发 展, 需要沿线国家共同推动, 区域合作组织协调, 建议通关协调机制, 改造瓶颈路段运输能力, 在通 关效率和单证简化方面保证运输时间和效率; 建立 与班列沿线国家海关的国际合作机制，签订海关相 关合作协定，促进报关互信、监管互认、执法互助; 支持更多的中欧班列项目纳入 “安智贸” 便利化 通关 [4]。

\section{（二）优化运输组织，提供全程物流服务}

加快境外经营网点建设, 加强与国外铁路合作, 联合铺画全程运行图, 建立班列运行信息交换机制, 加大班列组织力度, 完善过程组织, 保障货源支撑, 实行全程监控, 强化应急处理, 提高班列正点率, 稳定既有直达班列, 发展中转班列, 结合中欧通道 实际运输能力, 组织制定中欧班列开行及优化调整 方案。

促进资源整合，不断创新运输服务模式。围绕 物流链全流程, 强化运输、仓储、配送、检验检疫、 通关、结算等环节高效对接, 提供一站式综合服务。 鼓励公路、水运、航空等运输方式与中欧班列有效 衔接，打造全程化物流服务链条。建立中欧班列客
户服务中心，为客户提供业务受理、单证制作、报 关报检、货物追踪、应急处置等服务。

\section{（三）完善价格机制，吸引多渠道资金投入}

应建立完善的价格机制。国内方面，遵循市场 规则, 根据运量变化情况, 建立灵活的中欧班列国 内定价机制。境外方面, 鼓励企业调研开拓海外市 场，提高返程货源，通过有效集中各地货源以及常 态化规模化的营运能力, 统一开展境外价格磋商, 掌握话语权并提高全程价格主导权。

在遵循国际多边程序和市场化规则的基础上, 利用亚洲基础设施投资银行、丝路基金等金融投资 机构，发挥各类投融资基金作用，支持中欧铁路通 道和节点建设；鼓励境内基金机构 “走出去”，以 股权投资、债务融资等方式支持中欧班列建设; 积 极吸引社会资本投入中欧班列营运环节，共享投资 收益。

\section{（四）推进平台建设，加强人才培养和科技创新}

积极推进物流公共信息服务平台建立。建立权 威性、各部门共同参与的国家层面的国际班列协调 服务机构 [5]，通过市场化、协商的方式，通过与 其他国家行政机关、企业联合，建设中欧班列信息 服务平台, 加强电子商务平台信息化和智能化建设, 优化国际物流信息获取及加工处理的方式，与沿线 各国铁路、海关、检验检疫部门开展数据交换与信 息共享，实现电子预报关和单据预审，实现列车实 时运输信息和班列在途跟踪信息, 推行单据电子化, 打通物流信息链, 迈入智慧物流, 逐步打造 “数字 化” 中欧班列。

培养专业过硬、素质优良的物流运营操作骨干 业务人才; 培养熟悉物流领域国际惯例与规则、精 通国际商贸知识和外语、具备国际视野的复合型人 才; 培养具有多元知识结构及储备的专家型技术人 才。利用国家科技创新平台，开展铁路物流科技装 备、冷链关键技术等研发工作。积极探索人工智能 技术应用，通过大数据云计算处理，将其广泛运用 到物流产业并直接参与到物流环节之中, 结合季节、 天气、交通等因素, 准确预测和分析物流成本，及 时设置或调整物流方案，使各环节高效衔接，以大 幅提高中欧班列运输时效性和灵活性, 助力其高质 量可持续性发展。 


\section{六、结语}

中欧班列正在从追求数量扩张向追求高质量可 持续性发展的道路上迈进，其发展目标也从最初的 为当地货物寻求出口通道, 到吸纳外地货源发展为 物流枢纽, 再到以通道带动贸易、以贸易聚集产业, 以产业创造价值的升级转变 [7]。共建 “一带一路” 关键是互联互通，落实以新亚欧大陆桥等经济走廊 为引领, 以中欧班列、陆海新通道等大通道和信息 高速路为骨架, 以铁路、港口、管网等为依托的互 联互通网络建设的国家战略部署, 为构建全球互联 互通互惠伙伴关系、实现共同繁荣发展的愿景提供 了新的机遇和广阔发展空间。中欧班列是 “一带一 路” 建设的重要平台, 将其打造成为具有国际竞争 力和良好商誉度的世界知名物流品牌, 实现高质量 可持续性发展，对进一步深化我国 “走出去” 企业 在国际市场上的宽度、密度、广度和深度，推动打 造中欧班列国际物流运输利益共同体意义深远。

\section{参考文献}

[1] 高柏, 甄志宏. 中欧班列——国家建设与市场建设 [M]. 北京: 社会科学文献出版社, 2017.

Gao B, Zhen Z H. The China-Europe Freight Train: State building and market building $[\mathrm{M}]$. Beijing: Social Sciences Academic Press(China), 2017.

[2] 吴刚, 陈兰芳, 郭茜, 等. “一带一路”战略下中欧班列可持续发
展对策研究 [J]. 交通运输工程与信息学报, 2017, 15(4): 1-10, 43.

Wu G, Chen L F, Guo Q, et al. A study on the sustainable development of China Railway Express in the strategy of "The Belt and Road" [J]. Journal of Transportation Engineering and Information, 2017, 15 (4): 1-10, 43.

[3] 许英明, 邢李志, 董现垒. “一带一路”倡议下中欧班列贸易通道 研究[J]. 国际贸易, 2019 (2): 80-86.

Xu Y M, Xing L Z, Dong X L. Research on the trade routes of China Railway Express under the Belt and Road initiative [J]. Intertrade, 2019 (2): 80-86.

[4] 王艳波. 中欧班列建设发展规划研究 [J]. 铁道运输与经济, 2017 (1): 41-45.

Wang Y B. Discussion on construction and development planning of China Railway Express [J]. Railway Transport and Economy, 2017 (1): 41-45.

[5] 崔艳萍, 武靖宇. 利用亚欧铁路运输通道提升中欧班列运行品质 的研究 [J]. 铁道运输与经济, 2017 (5): 68-72.

Cui Y P, Wu J Y. Study on increasing operation quality of China Railway Express by using Asia-Europe Railway transport corridor [J]. Railway Transport and Economy, 2017 (5): 68-72.

[6] 张文, 彭胜, 秦乾, 等. 关于建立中欧班列质量评价指标体系的 探讨 [J]. 铁道运输与经济, 2019 (3): 85-89.

Zhang W, Peng S, Qin Q, et al. A reflection on the establishment of the quality evaluation index system of China Railway Express [J]. Railway Transport and Economy, 2019 (3): 85-89.

[7] 商务部国际贸易经济合作研究院.中欧班列贸易通道发展报告 [R]. 北京: 商务部国际贸易经济合作研究院, 2019.

Chinese Academy of International Trade and Economic Cooperation of Ministry of Commerce. Development report of the trade routes of China Railway Express [R]. Beijing: Chinese Academy of International Trade and Economic Cooperation of Ministry of Commerce, 2019. 